\title{
IMPLEMENTASI KEBIJAKAN ABSENSI BIOMETRIK TERHADAP DISIPLIN DAN KINERJA APARATUR SIPIL NEGARA PADA BIRO UMUM SEKRETARIAT DAERAH PROVINSI KALIMANTAN TENGAH
}

\author{
Implementation of Biometric Attendance Policy on The Discipline and Performance of Civil \\ State Apparatus on General Bureau of Regional Secretariat in Central Kalimantan Province
}

\section{Erry Apriyanti' \\ Nicodemus ${ }^{2}$ \\ Milka $^{3}$}

Universitas Muhammadiyah Palangkaraya, Palangka Raya, Central Kalimantan, Indonesia

email:rye497I@gmail.com

\section{Kata Kunci: \\ Implementasi \\ Kebijakan \\ Absensi \\ Disiplin \\ Kinerja}

\section{Keywords:}

Implementation

Policy

Attendance

Discipline

Performance

\section{Accepted}

Januari 2020

\section{Published}

April 2020

\begin{abstract}
Abstrak
Penelitian ini bertujuan untuk mengetahui sejauhmana penerapan kebijakan absen Biometrik serta dampaknya terhadap Disiplin dan Kinerja Aparatur Sipil Negara Pada Biro Umum Sekretariat Daerah Provinsi Kalimantan Tengah berdasarkan Peraturan Pemerintah Nomor 53 Tahun 2010 tentang Disiplin Pegawai Negeri Sipil.

Penelitian ini meneliti tentang Implementasi Kebijakan maka peneliti menggunakan teori implementasi kebijakan Model Donald Van Metter and Carl Van Horn (Agustino,2016:133). Model Pendekatan Top-Down pada teori ini merupakan sebuah performansi dari suatu pelaksanaan kebijakan yang pada dasarnya secara sengaja dilakukan untuk meraih kinerja implementasi kebijakan publik yang tinggi yang berlangsung dalam hubungan dengan enam variabel yang mempengaruhi Kinerja Implementasi Kebijakan yaitu ukuran dan tujuan kebijakan, sumber daya, karakteristik agen pelaksana, Sikap atau kecenderungan (disposition) para pelaksana, komunikasi antar organisasi dan aktivitas pelaksana serta lingkungan ekonomi, sosial dan politik dengan mengandalkan bahwa implementasi kebijakan berjalan secara linier dari keputusan politik yang tersedia, pelaksana dan kinerja kebijakan publik. Tipe penelitian yang digunakan adalah deskriptif kualitatif. Teknik pengumpulan data menggunakan observasi, mengadakan wawancara dan dokumentasi, kemudian data dianalisis secara reduksi (dirangkum), penyajian data dan Verifikasi.
\end{abstract}

Dari hasil penelitian menunjukkan bahwa penerapan kebijakan absensi biometrik sudah dilaksanakan dengan baik hal ini terlihat dari peningkatan disiplin dan kinerja ASN yakni sudah memenuhi jam masuk (apel pagi) dan jam pulang kantor, SDM memiliki karakter disiplin, Komunikasi antara pimpinan dan bawahan terjalin selalu setiap waktu secara berjenjang, lingkungan kerja menunjukan suasana yang kondusif. Dampak implementasi kebijakan absen biometrik terhadap disiplin meningkat dan dibarengi dengan peningkatan kinerja.

\begin{abstract}
This research aims to determine the implementation of biometric absence policy and its impact on the discipline and performance of civil state apparatus at the General Bureau of Central Kalimantan Provincial secretariat based on government regulation Number 53 the year 2010 about civil servants ' discipline.

This study examined the policy implementation of the researchers using the Model implementation theory of Donald Van Metter and Carl Van Horn's policy (Agustino,2016:133). The Top-Down approach Model in this theory is a performance of a policy implementation that is essentially intentionally done to achieve a high performance implementation of public policy that takes place in a relationship with six Variables that affect the performance of the policy implementation are the size and objectives of policies, resources, the characteristics of implementing agents, attitudes or tendencies (disposition) of executives, communication between organizations and implementing activities and Economic, social and political environment by relying on that policy implementation runs linearly from available political decisions, executor and public policy performance. The type of research used is qualitative descriptive. Data collection techniques use observations, conduct interviews, and documentation, and then data is analyzed by reduction, data presentation and verification.
\end{abstract}

From the results showed that the application of the biometric attendance policy has been performed well this is seen from the improvement of the discipline and performance of ASN which is already meet the hours of entry (morning apple) and hours of office, HR has character Discipline, communication between leaders and subordinates is always established at all times in a level, the working environment shows a conducive atmosphere. The impact of policy implementation of biometrics absent discipline increases and is coupled with improved performance. 


\section{PENDAHULUAN}

Reformasi Birokrasi menjadi langkah strategis untuk membangun aparatur negara agar lebih berdaya guna dan berhasil guna dalam mengemban tugas umum pemerintahan dan pembangunan nasional. Untuk mewujudkan hal tersebut, maka langkah awal yang harus dilakukan adalah meningkatkan disiplin pegawai. Disiplin yang dimaksud mencakup unsur-unsur kepatuhan dan ketaatan terhadap peraturan-peraturan yang berlaku, besarnya rasa tanggung jawab terhadap tugas-tugas yang diberikan, serta sanggup menjalankan dan tidak mengelak untuk menerima sanksi dan melaksanakannya dengan sungguh-sungguh apabila melanggar tugas dan wewenang.

Pada dasarnya jiwa kedisiplinan tersebut mutlak harus dimiliki, ditanamkan dan dipupuk oleh setiap Pegawai Negeri Sipil sebagai aparatur birokrasi dalam pelaksanaan berbagai rutinitas keseharian, hal ini mengingat hubungan antara disiplin dan Kinerja sehingga pelayanan prima pada masyarakat yang juga merupakan tujuan dari reformasi birokrasi.

Untuk mengukur sejauh mana tingkat kedisiplinan PNS salah satu cara yaitu dilihat dari kehadiran sehari-hari saat datang dan pulang. Apakah kehadiran mereka sudah memenuhi ketentuan waktu yang ditetapkan atau belum. Tingkat Kehadiran mereka dapat dibuktikan dengan sebuah daftar hadir atau absensi. Absensi yang diisi dengan tandatangan saat datang dan saat pulang bukan dirapel (ditanda tangani sekaligus), bukan rekayasa dan juga bukan sekedar penuh ditandatangani dalam waktu yang bersamaan. Untuk Menghindari kemungkinan terjadinya pelanggaran/ kecurangan tanda tangan, yang merupakan salah satu indicator kedisiplinan kerja, pemerintah mengeluarkan kebijakan yaitu dengan menggunakan mesin absensi elektronik menggantikan system absensi manual yang digunakan selama ini. Kebijakan ini merujuk pada pemberlakuan Peraturan Pemerintah Nomor 53 Tahun 2010 tentang disiplin Pegawai Negeri Sipil.
Sejak dikeluarkannya peraturan tersebut, system absensi di birokrasi pemerintah dan Lembaga berganti menggunakan sistem absensi elektronik. Peraturan tersebut bertujuan agar setiap Pegawai Negeri Sipil dapat berperilaku disiplin dengan mentaati setiap kebijakan yang telah ditetapkan Pemerintah.

Implementasi Kebijakan absensi biometrik di Satuan Organisasi Perangkat Daerah Pemerintah Provinsi Kalimantan Tengah telah ditekankan kembali dengan diterbitkannya Peraturan Gubernur Kalimantan Tengah Nomor I Tahun 2015 tentang disiplin kerja Pegawai Negeri Sipil di lingkungan Pemerintah Provinsi Kalimantan Tengah. Pada Bab III pasal 10 Ayat (I) PNS mengisi daftar hadir pada setiap hari kerja dengan menggunakan sistem daftar hadir elektronik (finger print) di satuan kerja masing-masing. Ayat (2) Pengisian daftar hadir sebagaimana dimaksud pada ayat (I) dilakukan satu kali pada saat masuk kerja dan satu kali pada saat pulang kerja.

Pada Lingkup Sekretariat Daerah Provinsi Kalimantan Tengah khususnya pada Biro Umum system absensi bukan hanya dilakukan dengan elektronik tetapi juga manual, hal ini dimaksudkan untuk mengevaluasi tingkat kehadiran aparatur sipil negara bukan hanya pada jam masuk kerja tetapi juga kehadiran pada apel pagi dan apel sore dan untuk mengantisipasi kemungkinan gangguan terkait jaringan dan daya listrik. Pemberlakuan daftar hadir/ absensi biometrik untuk mencapai disiplin kerja. Dengan menggunakan absensi biometrik, jam datang dan pulang akan direkam langsung dan tidak dapat direkayasa, kecuali jika alat ini sedang rusak atau kendala kerusakan lain maka akan tetap diperlukan absensi manual. Hal ini juga menjadi dasar bagi pemerintah dalam melakukan pemberian, penambahan dan pengurangan tunjangan kinerja Pegawai Negeri Sipil dilingkungan Pemerintah Provinsi Kalimatan Tengah. Tunjangan diberikan dengan melihat kinerja atau capaian hasil kerja. Hal ini dibuktikan juga dengan laporan Sasaran Kinerja Pegawai (SKP). Yang mana 
bermuatkan Tugas pokok dan Fungsi Pegawai dalam pelaksanaan sehari-hari, artinya disiplin kerja bukan hanya tepat waktu saat hadir datang dan pulang.

Menurut Grindle (Nugroho, 2004) menjelaskan bahwa, yang dimaksud dengan keberhasilan implementasi dipengaruhi oleh dua variable besar yaitu isi kebijakan (content of policy) dan lingkungan implementasi (context of implementation). Dalam penggunaan absen elektronik sidik jari (finger rpint) ini merupakan salah satu wujud dari kebijakan pemerintah yang tertuang dalam Peraturan Pemerintah Nomor 53 tahun 2010 tentang Disiplin Pegawai Negeri Sipil. Sehingga dalam hal ini lebih lanjut akan menjelaskan penerapan dan dampak penerapan kebijakan absensi biometrik terhadap disiplin dan kinerja Aparatur Sipil Negara Pada Biro Umum Sekretariat Daerah Provinsi Kalimantan Tengah.

\section{METODOLOGI}

Dalam Penelitian ini menggunakan Pendekatan deskriftif yang bertujuan untuk menjelaskan atau mendiskripsikan suatu keadaan, peristiwa, objek apakah orang, atau segala sesuatu yang terkait dengan variabel-variabel yang bisa dijelaskan baik dengan angka-angka maupun kata-kata. Sehingga pada penelitian ini, metode yang digunakan adalah metode kualitatif dengan pendekatan deskriptif, guna menjabarkan atau mendeskripsikan gambaran penelitian pada suatu keadaan yang sebenarnya bagaimana Implementasi Kebijakan absen Biometrik terhadap disiplin dan kinerja yang ada pada Biro Umum Sekretariat Daerah Provinsi Kalimantan Tengah.

Penelitian dilaksanakan di Biro Umum Sekretariat Daerah Provinsi Kalimantan Tengah. Data penelitian ini diperoleh dari hasil pengamatan langsung, wawancara, dan mengumpulkan dokumen-dokumen. Adapun informan dalam penelitian ini adalah Kepala Biro Umum, Kepala Sub Bagian Tata Usaha, Petugas Operator Absensi dan beberapa Pegawai yang ditemui pada saat absensi. Serta data pendukung berupa gambar/foto, data pegawai, data absensi biometrik, dan Peraturan Gubernur Kalimantan Tengah Nomor I tahun 2010.

\section{HASIL DAN PEMBAHASAN}

Sekretariat Daerah sebagai pusat Pemerintahan Daerah dalam hal menciptakan Good Governance dan mewujudkan visi dan misi KALTENG BERKAH (Bermartabat, Elok, Religius, Agamis dan Humanis) serta dalam rangka pembangunan daerah tentunya harus didukung dengan kemampuan pegawai negeri yang berkualitas. Untuk itu, perlu adanya pengembangan kinerja pegawai negeri sehingga dapat memberikan kinerja yang maksimal dalam melaksanakan tugasnya. Sama seperti instansi pemerintah lainnya yang memiliki kendala dalam peningkatan kinerja pegawai negeri sipil, kantor Sekretariat Daerah Provinsi Kalimantan Tengah juga demikian, Juga masih banyak keluhan-keluhan masyarakat yang menyatakan buruknya kinerja pegawai negeri sipil dalam pemberian pelayanan bagi masyarakat. Masih banyak pegawai yang mangkir dalam melaksanakan tugas dan fungsinya, seperti banyaknya pegawai negeri yang tidak megikuti apel pagi, dan tidak berada ditempat disaat masih jam kerja atau banyak pegawai yang berada pada warung di saat jam kerja.

Kinerja aparatur pemerintah tersebut juga sering ditekankan langsung oleh Sekretaris Daerah Provinsi Kalimantan Tengah selaku Pembina Kepegawaian melalui Biro Organisasi Sekretariat Daerah Provinsi Kalimantan Tengah dan Badan Kepegawaian Daerah Provinsi Kalimantan Tengah. Dengan menghimbau agar para aparatur pemerintah bersikap lebih disiplin, baik disiplin waktu jam masuk dan jam pulang kantor, disiplin dalam berpakaian dinas dan disiplin dalam menaati semua peraturan yang berlandaskan Undang-undang dan Pancasila.

Pada penelitian implementasi kebijakan absensi biometric ini, peneliti menggunakan teori implementasi kebijakan model Donald Van Metter \& 
Carl Van Horn (Leo Agustino, 2016:133) teori ini digunakan karena memiliki variabel-variabel yang dirasa mampu untuk menunjukan kinerja dari implementasi kebijakan yakni (I).Ukuran dan tujuan kebijakan, (2). Sumber daya, (3) karaketristik agen pelaksana, (4) sikap atau kecenderungan (dispotion) para pelaksana,

(5) Koordinasi antar organisasi dan aktivitas pelaksana,

(6) lingkungan ekonomi, social dan politik. Hal ini diuraikan sebagai berikut :

I. Ukuran dan Tujuan kebijakan

Ketepatan waktu kehadiran sangatlah penting bagi Aparatur Sipil Negara sebagaimana yang telah ditetapkan oleh Pemerintah, sebagai aparat yang bertugas memberikan pelayanan kepada public maka ketentuan jam kerja selama 5 hari kerja selama seminggu yakni 7,5 jam atau $37 \mathrm{jam} /$ minggu sebagaimana ketentuan jam kerja berikut :

Hari Senin-Kamis :

Pukul 07.00-15.30 WIB :

- 07.00-12.00 WIB (jam kerja pagi)

- 12.00-13.00 WIB (istrirahat)

- I3.00-I5.30 WIb (jam kerja siang).

Hari Jum'at :

Pukul 07.00-15.30 WIB :

- 07.00-II.30 WIB (jam kerja pagi)

- II.30-13.00 WIB (istrirahat)

- I3.00-I5.30 WIb (jam kerja siang).

Dalam pengaplikasian absensi biometric, Biro Umum telah membuat Standard Operating Prosedure (SOP) ketentuan waktu absensi biometric yakni :

Hari Senin s.d Kamis

: Pukul 06.30 s.d 07.30 WIB (apel masuk pagi)

: Pukul I5.30 s.d I8.00 WIB (apel masuk siang)

Hari Jum'at

: Pukul 06.00 s.d 07.00 WIB (apel masuk pagi)

: Pukul I5.30 s.d I8.00 WIB (apel masuk siang)

Sementara itu guna mengontrol disiplin kehadiran pegawai pada saat pelaksanaan apel pagi maupun apel sore maka digunakan absensi manual yang dilaksanakan secara langsung pada saat berada dilapangan halaman kantor.

Kebijakan Absensi tersebut sudah jelas sejalan dengan teori bahwa sebuah implentasi kebijakan akan berjalan sukses bilamana memiliki arah dan tujuan yang jelas, dari pernyataan Kepala Biro Umum dapat disimpulkan sebagai berikut :

Pertama, tujuan implementasi kebijakan absensi biometric adalah untuk meningkatkan disiplin dn kinerja ASN. Hal ini telah menjadi tujuan dan cita-cita dasar dari implementasi kebijakan absensi biometric pada Biro umum.

Kedua, standar keberhasilan implementasi kebijakan absensi biometric adalah menyadari adanya kewajiban dan tanggung jawab sebagai seorang ASN yang salah satunya adalah memenuhi disiplin kehadiran dengan tujuan peningkatan kinerja.

2. Sumber Daya

Keberhasilan implementasi kebijakan sangat didukung oleh sumber daya. Baik itu SDM maupun sumber daya pendukung lainnya. Implementasi Kebijakan absensi biometric pada Biro Umum dilihat dari sumber daya yaitu ; pertama, kesiapan para ASN dlam menjalani perubahan dari absensi manual ke absensi biometric, kedua, respon atau tanggapan ASN dalam menyambut perubahan proses absensi tersebut, ketiga, melihat sarana dan prasarana yang digunakan dalam mendukung implementasi kebijakan.

Agar dapat mengetahui hal tersebut, peneliti melakukan wawancara Bersama Kasubbag Tata Usaha dan beberapa ASN yakni :

"Sebelum absensi biometric ini diterapkan, kami sudah mendapatkan peraturannya, jadi, langsung disosialisasikan kepada seluruh ASN, sehingga mereka sudah siap. Atas petunjuk pimpinan lalu kami mulai mengadakan peralatan absensi biometric yang mana sebelumnya hanya menggunakan absensi secara manual, dan sangat rentan sekali dengan rekayasa, dengan adanya absensi biometric ini setidaknya meminimalisir hal tersebut sehingga 
bisa lebih transparan lagi dalam hal kehadiran ASN.(wawancara dengan Kasubbag Tata Usaha, 3 Oktober 2019)".

Tidak dipungkiri bahwa memang ada ASN yang keberatan dengan berbagai alasan. Akan tetapi setelah melalui uji coba dan sosialisasi bahwa absensi biometric bisa dilaksanakan dan tidak ada hambatan yang berarti.

Gambar I.

Absensi Sidik Jari dan Scan Wajah

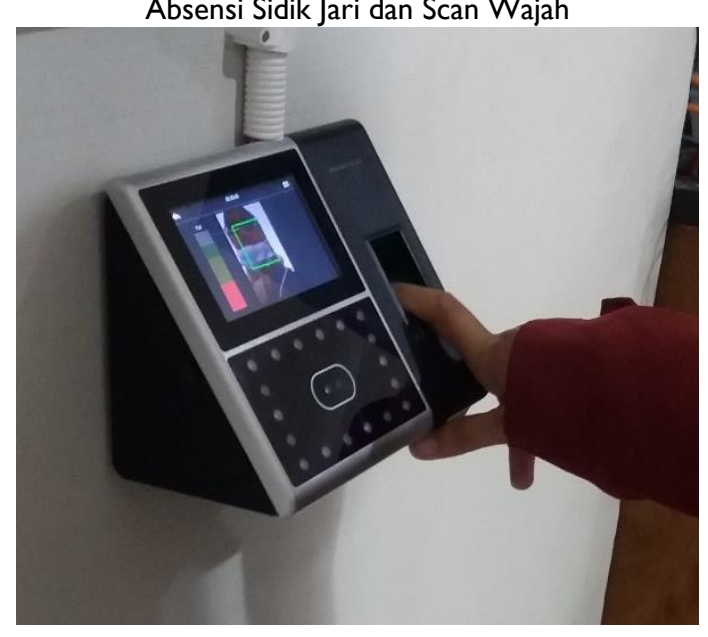

Dari beberapa hasil wawancara dan beberapa Gambar I diatas dapat ditarik kesimpulan bahwa implementasi kebijakan tersebut telah disosialisasikan. Sehingga tidak ada alasan tidak mengetahui peraturan tersebut, karena hal tersebut dilaksanakan dalam rangka peningkatan kualitas ASN sesuai dengan Peraturan Gubernur Kalimantan Tengah nomor I tahun 20I5.

\section{Agen Pelaksana}

Pada implementasi kebijakan yang menjadi pusat perhatian adalah para agen pelaksana, jika para pelaksana telah melaksanakannnya dengan baik, maka berarti implementasi kebijakan telah dilaksanakan dengan baik pula, begitupun sebaliknya.

Implementasi kebijakan dilihat dari karakteristik agen pelaksana yaitu meliputi stake holder dalam menerapkan absensi biometric, plaksanaan serta mekanisme dan bentuk sanksi yang diberikan kepada ASN yang belum menaati aturan.
Implementasi kebijakan absensi biometric pada Biro Umum memang sudah cukup baik dn kondusif. Rata-rata para ASN datang lebih awal kemudian apel pagi dan memulai pekerjaan tingkat disiplin ASN dapat terlihat pada gambar hasil cetak daftar hadir sebagian ASN dibawah ini :

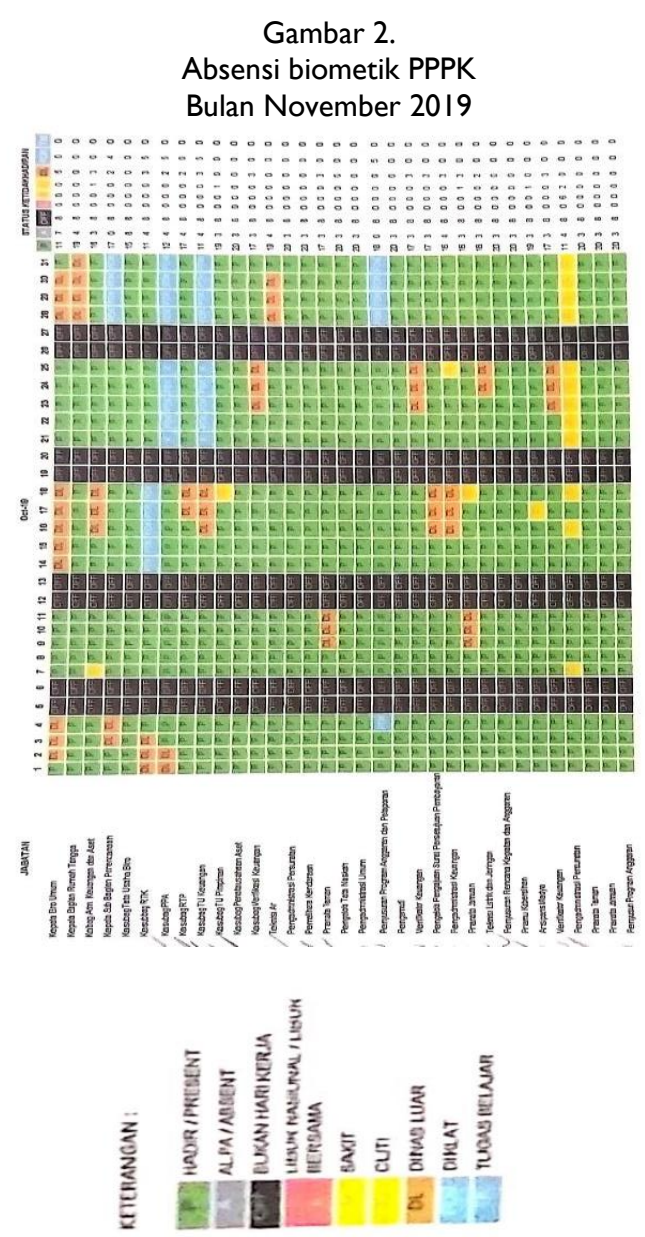

Gambar 2 adalah salah satu contoh hasil cetak daftar hadir biometric ASN. Pada Gambar tersebut menunjukan bahwa implementasi kebijakan absensi biometric sudah menunjukan hasil yang baik. Pendataannya terekam jelas dan akurat.

4. Sikap atau kecenderungan (disposisi) Pelaksana

Keberhasilan implementasi kebijakan sangat dipengaruhi oleh sikap para pelaksana. Implementasi kebijakan absensi biometric pada Biro Umum dilihat dari kecenderungan para pelaksana mencakup beberapa hal berikut yakni respon ASN dalam mendukung kebijakan absensi 
biometric an aktivitas setelah melakukan absensi biometric.

Absensi biometric ini sudah diterapkan sejak tahun lalu dan sudah disosialisasikan kemudian pada bulan maret 2019 sudah terkoneksi secara online ke BKD, hal ini berkaitan dengan pembayaran uang makan, dan hinngga sekarang penerapannya tidak ada hambatan.

Sehingga dapat disimpulkan bahwa ASN tidak keluyuran setelah melaksanaan absensi. Disiplin meningkat sehingga menunjang tercapainya kinerja yang baik.

5. Koordinasi Komunikasi Antar Organisasi dan aktivitas pelaksana

Komunikasi dan koordinasi sangat diperlukan dalam rangka menjalankan implementasi kebijakan absensi biometrik, sebab dengan koordinasi yang baik akan mampu melihat berbagai kelemahan dan kekuatan dalam implementasi kebijakan tersebut. Dengan demikian maka kemungkinan pelanggaranpelanggaran akan semakin kecil terjadi.

Implementasi kebijakan pada Biro umum mencakup dua hal yaitu koordinasi pimpinan terhadap ASN dan sosialisasi yang diberikan dalam memberikan pemahaman tentang implementasi kebijakan absensi biometrik.

Untuk mengetahui bagaimana koordinasi yang dilaksanakan peneliti menanyakan hal tersebut kepada Kepala Biro Umum langsung selaku pimpinan

"Koordinasi yang saya lakukan adalah menanyakan bagaimana apakah terdapat kendala dalam pelaksanaan absensi tersebut, termasuk penggunaan, sarana, dan fasilitas penunjang lainnya. Kemudian saya menyampaikan kepada seluruh ASN lingkup Biro Umum bahwasanya absensi ini akan direkap dan sebagai bahan evaluasi setiap bulannya, sehingga dengan demikian mereka akan lebih disiplin, sejauh ini saya belum ada menemukan atau mendengar kesulitan yang dihadapi.(wawancara Kepala Biro Umum, tanggal 5 oktober 2019).
6. Lingkungan Ekonomi, Sosial dan Politik

Keberhasilan dari penerapan sebuah kebiajakan dapat ilihat dari kondisi dan kerja di tempat tersebut. Mulai dari kantor, para pegawainya, kinerja, capaian dan lain sebagainya. Dalam hal ini, peneliti juga telah melakukan penghimpunan data untuk melihat bagaimana kondisi kerja dari implementasi kebjakan absensi biometrik.

Beberapa hal yang mencerminkan keberhasilan implementasi kebijakan absensi biometrik dapat dilihat dari lingkungan antara lain perubahan sikap disiplin ASN dan kinerja sebelum dan setelah implementasi kebijakan absensi biometrik

\section{Dampak Kebijakan Absensi Biometrik}

Berdasarkan hasil peneliti, peneliti menemukan adanya dua dampak dari implementasi kebijakan absensi biometric yakni terhadap disiplin dan kinerja yaitu :

a. Terhadap disiplin

Berdasarkan Analisa data hasil penelitian yang dilakukan bahwa penerapan absensi biometric dapat meningkatkan kedisiplinan para Aparat Sipil Negara di lingkungan Biro umum Setda Prov. Kalteng. Hal ini terlihat dari ramainya saat para ASN melaksanakan absensi dan apel pagi maupun apel sore, dan tidak ditemukan adaya sanksi atas pelanggaran disiplin atau sejenisnya.

b. Terhadap Kinerja

Berdasarkan pada penelitian bahwasanya implementasi kebijakan absensi biometric pada Biro Umum Setda Provinsi Kalimantan Tengah terhadap kinerja yaitu :

I) ASN melakukan absensi biometric ketika tiba dikantor

2) Setelah melakukan asbsensi, para ASN segera menuju ruang kerja masing-masing dan melaksankan rutinitas

3) Para ASN keluar dan santai pada saat jam istirahat atau menjelang waktu sholat Dzuhur. 
4) Para ASN tetap berada dikantor meskipun pekerjaan telah selesai

5) Para ASN membuat Sasaran Kinerja pegawai (SKP)

Dari pernyataan tersebut dapat disimpulkan bahwa sejak menerapkan absensi biometric para ASN lebih tertib, lebih disiplindan kinerja membaik.

\section{KESIMPULAN}

Implementasi Kebijakan Absensi biometric terhadap disiplin dan kinerja Aparatur Sipil Negara pada Biro Umum Sekretariat Daerah Provinsi Kalimantan Tengah sudah menunjukkan tingkat yang lebih baik (optimal). Dampak penerapan kebijakan absensi biometrik terhadap disiplin dan kinerja Aparatur Sipil Negara Pada Biro Umum Sekretariat Daerah Provinsi yaitu telah memberikan dampak positif. Ada dua hal yang menjadi dampak positif yakni meningkatnya tingkat disiplin dan juga dibarengi dengan peningkatan kinerja pegawai.

Diharapkan kepada Pimpinan agar selalu secara berjenjang melakukan pengawasan, pembinaan dan Menegaskan sanksi (punishment) sebagai konsekuensi atas ketidak disiplinan para Aparatur Sipil Negara agar pelaksanaan kebijakan absensi elektronik yang telah dibuat saat ini bisa berjalan dengan efektif. Serta Hendaknya Kepala Biro Umum Sekretariat daerah provinsi Kalimantan tengah agar lebih intensif melakukaan komunikasi antar organisasi dan disposisi koordinasi yang berkaitan dengan Absen Biometik, kinerja dan disiplin dalam melaksanakan kegiatan pada saat jam kerja khususnya, saat jam kerja berlangsung, sesuai dengan peraturan Pemerintah Nomor 53 Tahun 2010.

\section{REFERENSI}

Anggara, Sahya. 2012. Ilmu Administrasi Negara. Bandung : CV.Pustaka Setia.

Agustino, Leo. 2008. Dasar-Dasar Kebijakan Publik. Bandung: CV.Alfabeta.

Dwiyanto,Agus. 2002. Penilaian Kinerja Organisasi Pelayanan Public. Yogyakarta: UGM.

Tahir, Arifin. 2014. Kebijakan Publik \& Transparansi Penyelenggaraan Pemerintah Daerah. Bandung : Alfabeta.

Mangkunegara.A.A Anwar Prabu. 2005. Evaluasi Kinerja Sumber Daya Manusia. Bandung: Refika Aditama

Mardiasmo. 2005. Akutansi Sektor Publik. Yogyakarta: Penerbit Andi.

Mulyadi Dedy. 2015. Studi Kebijakan Publik dan Pelayanan Publik. Bandung: Alfabeta.

Pasolong, Harbani. 20I0. Teori Administrasi Publik. Bandung. Alfabeta.

Prasetyo,irawan. 200I. Analisis kinerja: panduan praktis untuk menganalisis kinerja Organisasi, kinerja proses dan kinerja pegawai. Jakarta: LAN.

Wahab, Solichin Abdul. 200I. Analisis Kebijaksanaan Dari Formulasi ke Penyusunan Model-Model Implementasi Kebijakan Publik. Malang : Bumi Aksara.

Winarno, Budi. 20I4. Kebijakan Publik (Teori, Proses dan Studi Kasus). Caps. Yogyakarta.

Widodo, Joko. 2016. Analisis Kebijakan Publik. Malang : Media Nusa Creative. 